\title{
Emotional Intelligence
}

\author{
Susheelkumarv Ronad ${ }^{1 *}$, Chetans Patali ${ }^{2}$, Kirankumartc $^{3}$, Smtpankajatc $^{4}$, Santosh S Ugargol ${ }^{5}$, Shridhar H \\ Gondabal $^{6}$ and Veeresh Nandagaon ${ }^{7}$ \\ ${ }^{1}$ Department of Psychiatric, India \\ ${ }^{2}$ Principal, Av School of Nursing, India \\ ${ }^{3}$ Department of Management Studies, India \\ ${ }^{4}$ Assistant Professor, India \\ ${ }^{5}$ Nursing Dimhans Dharwad, India \\ ${ }^{6}$ Indira Gandhi Institute of Child Hospital, India \\ ${ }^{7}$ Associate Professor, India \\ *Corresponding author: Susheelkumarv Ronad, Department of psychiatric nursing Dimhans dharwad, India \\ Submission: 鮆 January 17, 2018; Published: 眥 February 22, 2018
}

\section{Introduction}

Emotional Intelligence (EQ or EI) is defined as the ability to understand, manage, and effectively express one's own feelings, as well as engage and navigate successfully with those of others. Studies show that, $90 \%$ of high performers at the work place possess high EQ, while $80 \%$ of low performers have low EQ. It is absolutely essential in the formation, development, maintenance, and enhancement of close personal relationships.

\section{There are Six Keys to Increase Emotional Intelligence}

\section{The ability to reduce negative emotions}

In order to change the way we feel about a situation, we must first change the way we think about it. For an instance as follows:

Reducing negative personalization: When you feel adversely about someone's behaviour, right away avoid jumping to a negative conclusion. Instead, come up with multiple ways of viewing the situation before reacting. For example, I may be tempted to think my friend didn't return my call because she's ignoring me, or I can consider the possibility that she's been very busy. When we avoid personalizing other people's behaviours, we can perceive their expressions more objectively. People do what they do because of them more than because of us. Widening our perspective can reduce the possibility of misunderstanding.

Reducing the fear of rejection: One of the best ways to manage your fear of rejection is to provide yourself with multiple options in important situations, so that no matter what happens, you have strong alternatives going forward. Avoid putting all of your eggs in one basket (emotionally) by identifying a viable Plan B, and also a Plan C, should Plan A not work out.

For example: Increased fear of rejection: "I'm applying for my dream job. I'll be devastated if they don't hire me." Decreased fear of rejection: "I'm applying for three exciting positions. If one doesn't pan out, there are two more I'm well qualified for."

\section{The ability to stay cool and manage stress}

Most of us experience some level of stress in life. How we handle stressful situations can make the difference between being assertive versus reactive, and poised versus frazzled. When under pressure, the most important thing to keep in mind is to keep our cool. Here are two quick tips:

A. Put cold water on your face and get some fresh air when you feel nervous and anxious. Our anxiety level can be reduced by Cool temperature. Avoid caffeinated beverages which can stimulate your nervousness

B. Energize yourself: If you feel fearful, depressed, or discouraged, try intense aerobic exercises. The way we use our body affects greatly the way we feel. As the saying goes-motion dictates emotion. As you experience the vitality of your body, your confidence will also grow.

The ability to be assertive and express difficult emotions when necessary

There are times in all of our lives when it's important to set our boundaries appropriately, so people know where we stand. It include exercising our right to disagree (without being disagreeable), saying "no" without feeling guilty, setting our own priorities, getting what we paid for, and protecting ourselves from duress and harm.

For an example the XYZ technique -

I feel $\mathrm{X}$ when you do $\mathrm{Y}$ in situation $\mathrm{Z}$.

Here are some examples: 
"I feel strongly that I should receive recognition from the company based on my contributions."

"I feel uncomfortable that you expect me to help you over my own priorities."

"I feel disappointed when you didn't follow through when you told me you would."

Avoid using sentences that begin with "you" and followed by accusation or judgment, such as "you are...,"'you should...," or "you need to...."'You" language followed by such directives put the listener on the defensive, and make them less likely to be open to what you have to say.

\section{The ability to stay proactive, not reactive in the face of a} difficult person

Most of us encounter unreasonable people in our lives. We may be "stuck" with a difficult individual at work or at home. It's easy to let a challenging person affect us and ruin our day. Here we have three quick steps:

A. When you feel angry and upset with someone, before you say something you might later regret, take a deep breath and count slowly to ten. In most circumstances, by the time you reach ten, you would have figured out a better way of communicating the issue, so that you can reduce, instead of complicate the problem. If you're still upset after counting to ten, take a time out if possible, and revisit the issue after you calm down.

B. Another way to reduce reactivity is to try to put yourself in the difficult individual's shoes, even for just a moment. For example, consider the person you're dealing with, and complete the sentence: "It must not be easy...."

C. "My child is being so resistant. It must not be easy to deal with his school and social pressures..."

D. "My boss is really demanding. It must not be easy to have such high expectations placed on her performance by management..."

E. To be sure, empathetic statements do not excuse unacceptable behaviour. The point is to remind you that people do what they do because of their own issues. As long as we're being reasonable and considerate, difficult behaviours from others say a lot more about them than they do about us. By depersonalizing, we can view the situation more objectively, and come up with better ways of solving the problem.

F. Set Consequence. The ability to identify and assert consequence(s) is one of the most important skills you can use to "stand down" a difficult person. Effectively articulated, consequence gives pause to the difficult individual, and compels her or him to shift from violation to respect.

\section{The ability to bounce back from adversity}

Life is not always easy. We all know that. How we choose the way we think, feel, and acting in relation to life's challenges can often make the difference between hope versus despair, optimism versus frustration, and victory versus defeat. With every challenging situation we encounter, ask questions such as "What is the lesson here?" "How can I learn from this experience?" "What is most important now?" and "If I think outside the box, what are some better answers?" The higher the quality of questions we ask, the better the quality of answers we will receive. Ask constructive questions based on learning and priorities, and we can gain the proper perspective to help us tackle the situation at hand.

\section{The ability to express intimate emotions in close, personal relationships}

The ability to effectively express and validate tender, loving emotions is essential to maintaining close personal relationships. In this case, "effective" means sharing intimate feelings with someone in an appropriate relationship, in a manner that's nourishing and constructive, and being able to respond affirmatively when the other person does the same.

Dr. John Gottman called the expression of intimate emotions as "bidding." Bidding is any method of positive connection between two people desiring a close relationship. For an illustration:

A. Verbal bidding can be among the followings: "How are you doing?"'”How are you feeling?"'”I love you."'I appreciate you."'I like it when we talk like this."'I'm glad we're spending this time together."'You're such a good friend."'I'm sorry."

B. Body language bidding is in the form of: positive eye contact, hugging, smiling, patting the elbow, arm around the shoulder.

C. Behavioural bidding can be: offering food or beverage, a personalized card, a thoughtful gift, a needed favour. Empathetic listing. Engaging in shared activities that create a closer bond. Close, healthy relationships bid with each other in ways large and small up to hundreds of times a day. The words and gestures can be a million variations, all of which say, in essence, "I care about you,"'I want to be connected with you," and "you're important in my life." Constant and consistent bidding is crucial in the maintenance and development of close, personal relationships. It's the vitamin of love

\section{Conclusion}

IQ which does not change significantly over a lifetime, our EQ can evolve and increase with our desire to learn and grow. So one should adopt the ability to reduce negative emotions, the ability to stay cool and manage stress, the ability to be assertive and express difficult emotions when necessary, the ability to stay proactive, not reactive in the face of a difficult person, the ability to bounce back from adversity and ability to express intimate emotions in close personal relationships.

\section{References}

1. Marazziti D, Di Muro A, Castrogiovanni P (1992) Psychological stress and body temperature changes in humans. Physiol Behav 52(2): 393-395.

2. Speck DF, Bruce DS (1978) Effects of varying thermal and apneic conditions on the human diving reflex. Undersea Biomed Res 5(1): 9-14. 
3. Winston AP, Hardwick E, Jaberi N (2013) Neuropsychiatric Effects of Caffeine. Advances in Psychiatric Treatment 11(6): 432-439.

4. Iancu I, Olmer A, Strous RD (2007) Caffeinism: History, Clinical Features, Diagnosis, and Treatment. In Smith BD, Gupta U, Gupta BS [Eds.]. Caffeine and Activation Theory: Effects on Health and Behavior, Harefuah 145(2): 147-151.
5. Daniel AG (1999) Change Your Brain, Change Your Life.

6. Steven PJ, Landers DM, Salazar W (1993) Exercise and anxiety reduction: Examination of temperature as an explanation for affective change. Journal of Sport \& Exercise Psychology 15(1): 63-76.
For possible submissions Click Here
Your subsequent submission with Crimson Publishers will attain the below benefits

- High-level peer review and editorial services

- Freely accessible online immediately upon publication

- Authors retain the copyright to their work

- Licensing it under a Creative Commons license

- Visibility through different online platforms

- Global attainment for your research

- Article availability in different formats (Pdf, E-pub, Full Text)

- Endless customer service

- Reasonable Membership services

- Reprints availability upon request

- One step article tracking system 